\title{
Discussions on the Electrical Construction Points in Indoor Decoration
}

\author{
Yongyi Zhang ${ }^{1, a}$ \\ ${ }^{1}$ Chongqing Real Estate College, Chongqing, China \\ azyy8405@qq.com
}

Keywords: indoor decoration, electrical engineering, construction points.

\begin{abstract}
In order to meet the people's higher requirements on the living environment, electrical engineering in indoor decoration mainly adopts the hidden construction. This paper analyses from the selection of electrical materials, construction points and quality controlling and proposes the operating procedures and methods of some common problems in electrical construction in indoor decoration, so as to reduce the potential safety issues in indoor environment caused by electrical construction.
\end{abstract}

\section{Introduction}

Presently, after buying a house from the real estate market, people will decorate it to meet their own requirements on the living environment. In order to save costs, some owners may hire the designers and construction companies with lower qualification for design or construction. The electrical load in indoor decoration is heavy and there are many kinds of electric equipment there. If the construction is only based on workers' experience, it may cause safety issues on the whole decoration. Therefore, being the indoor decoration practitioners or owners, they should understand some electrical construction points in indoor decoration, which will be beneficial to the entire decoration.

\section{Selection of electric materials}

Selection of strong electric wire. Strong electric wires in indoor decoration projects usually choose the three kinds of copper hard core wire with an cross sectional area of $2.5 \mathrm{~mm}^{2}, 4 \mathrm{~mm}^{2}$ and 6 $\mathrm{mm}^{2}$ respectively. Among these, in order to guarantee electrical loads of each circuit, copper hard core wire with a cross sectional area of $2.5 \mathrm{~mm}^{2}$ is used as illuminating circuit, that of $4 \mathrm{~mm} 2$ is used as socket circuit and that of $6 \mathrm{~mm}^{2}$ is used as air condition circuit[1]. But, currently some decoration companies will lower a cross sectional grade of corresponding circuit to reduce construction cost when choosing wires. Consequently, it has virtually increased the possibility of potential safety hazard. Meanwhile, for the purpose of convenient distinction in construction, the PVC insulation sleeve with copper hard core wire has many colors. Generally, the red is used for firing line, on one hand, and the yellow, the green and the blue are used for null line on the other. Besides, the dual green-yellow color line serves as earth wire. The usage of these colors for wires can be selected by oneself according to his customs in construction.

Selection of weak electric wire. Weak electric wires in indoor decoration projects mainly include telephone wire, network cable, closed wire and audio cable. In order to ensure low attenuation and few crosstalks in telephone signal transmission, the selection of telephone wire often requires shielding function. It means that there are nets shielding structure developed by copper wire or aluminum foil around the telephone wire. And the performance of the copper wire is better than that of aluminum foil. Moreover, the ordinary telephone usually uses the 2 cores telephone wire while video telephone uses 4 cores. When installing DIY home network, network cable usually chooses shielded twisted pair covered by aluminum foil outside to reduce radiation. And the selection of closed wire mainly focuses on that whether the braid of wire is tight or not. The tighter the better the shielding function is, and the clearer the television signal is. Besides, it also depends on the degree of thickness of copper wire. The thicker the copper wire, the better the antimagnetic function and the 
anti-interference signal are. Finally, in terms of the selection of audio cable, on market main speaker generally selects audio cable with over 300 cores and surround sound selects that with 200-core[1].

Selection of PVC conduit. PVC conduit, being buried within wall or structural layer, is chiefly used for connecting all kinds of wires in indoor decoration projects which plays the role to protect interior electric wires from damage. The nominal outside diameter of familiar conduits in decoration includes $16 \mathrm{~mm}, 20 \mathrm{~mm}, 25 \mathrm{~mm}, 32 \mathrm{~mm}$ and $40 \mathrm{~mm}$ etc.. And in home decoration the two usual kinds of PVC conduits are $16 \mathrm{~mm}$ and $20 \mathrm{~mm}$.

Selection of PVC Silicone Fiberglass Sleeving. It is known as PVC Silicone Fiberglass Sleeving which is primarily used for connecting the intersections of PVC conduits. It can help to avoid the inconvenience of differentiating structure surface course construction due to the overlapped cross of conduits. Moreover, the diameter of selected PVC Silicone Fiberglass Sleeving generally supports the use of PVC conduit[1]. (As shown in Figure1)

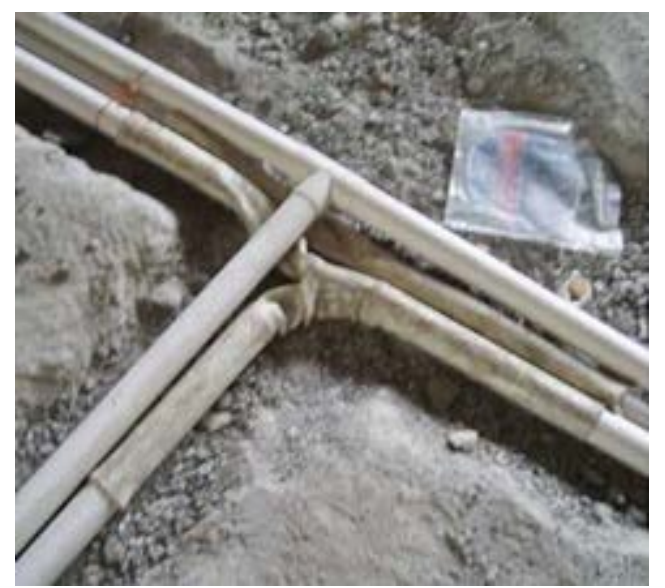

Figure 1 the using diagram of PVC Silicone Fiberglass Sleeving

Selection of strong and weak electric box. The strong electric box is mainly selected based on the power distribution circuit in construction. The common strong electric box has 8 circuits, 10 circuits, 16 circuits and 20 circuits etc.. In home decoration, $300 \mathrm{~mm} \times 240 \mathrm{~mm} \times 120 \mathrm{mmstrong}$ electric box with 10 circuits is usually took. But there are not specific criteria for choosing weak electric box. One can select the box that has general function or the intelligent one depend on the actual situation in construction.

\section{Main points of electric construction}

Laying of pipe line. According to the requirements of design drawing, the wires in all circuits should be protected by conduit in order to be benefit for second maintenance. It is not allowed to directly lay electric wires on the suspended ceiling or within the ground, which may have influence on the service life of wires and the solution of the wires' possible problems in future. At the part that the conduit needs to bend, the dedicated spring must be used instead or the elbow can be used to connect the location in order to make the diameter of the bended part keep consistent with that of the not bended one ( as shown in Figure 2). Meanwhile, it is better that the braiding number in spool is a group of circuit. And the way that multi-groups of circuit in one spool are braided is not advocated, as it is not favorable for heat dissipation of circuit during electric using process. Surface conduit in ceiling should meet the requirements of running rules and is not allowed to be fixed on the ceiling joist or suspender. 


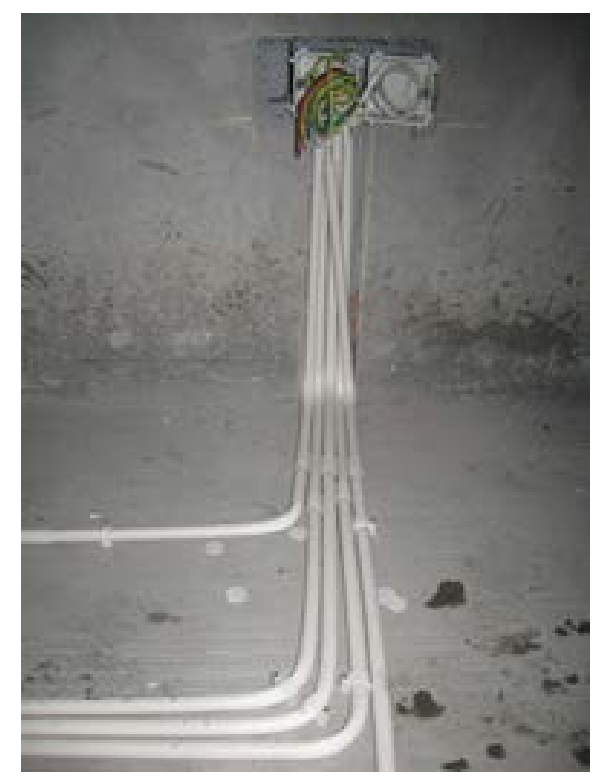

Figure 2 the conduit bending diagram

Laying of wire. When laying wire, the sub-circuits are generally arranged as one circuit for lights, three or four circuits for socket and one circuit for each air condition respectively. Meanwhile, the color of wire for firing wire, zero line and earth wire should also be settled. And the wire cannot bend in the conduit. Junction in the conduit is also forbid. Moreover, the junction part outside the conduit should be conducted tin-rinsing work based on national regulations. Besides, this position should also be intertwined together by two-layer tapes that one of them is high pressure resistant and corrosion resistant and another is waterproof. More importantly, earth wire is definitely essential for the whole home electric system.

Notes for restroom electrical installation. It is not encouraged that some decoration projects do not recover the original partial equipotential system in restroom after destroying. The restroom always plays the role as bathroom. When people is bathing, the human skin becomes wet, and impedance is reduced so that the lesser voltage conducted through metallic conduit can cause electric shock accident. Therefore, "partial equipotential bonding" in restroom can make the potential existed identically in the whole room to make people be free from dangerous touch voltage. As a result, after decoration, the broke partial equipotential system should be recovered as soon as possible.

\section{The control of electric construction quality}

Construction preparation stage. A construction drawing is the premise and gist in construction period. Only when one analyzes the drawing in detail and knows all systems in construction fairly well, he can find problems and correct them on the scene and precontrol the construction quality. At each stage before electric construction, drawings must be checked carefully to ensure the safety, accuracy and quality reliability. Before civil construction, electric installation personnel should check the civil engineering and electric construction drawing together with civil construction technical personnel in case of the omission and mistake. The electrician should learn to understand civil construction drawing and comprehend the construction schedule and methods. And they also should check carefully whether the electric installation method prepared by themselves adjusts with the civil construction of the project or not.

Foundation construction stage. When constructing foundation engineering, the electrician should cooperate with civil engineering personnel in time to obligate and pre-embed professional strong and weak electric cable through-wall pipe and water-stopped flapper for home entrance service. In order to avoid that the electric construction will break waterproof layer and make the wall leak, this work requires that professional electric construction should be finished before the civil engineering conducting wall waterproof; in terms of the embedded parts such as iron pieces, elevator, wood brick, 
suspender bay bolt and foundation fashioned iron for power distribution cabinet, the electrician should cooperate with civil engineering personnel to prepare in advance and construct them in right place. Moreover, omission is not allowed.

The construction stage of main parts. In monitoring electric quality, the connection and coordination part of the three key equipments as powder distribution unit, power cable and distribution box should be confirmed. And then to conduct look-ahead monitoring on the basis of regulations, the precontrol of the construction' s quality can be accomplished. Secondly, after successfully monitoring primary parts, the means to promote work in all areas by drawing upon the experience gained on key points must be took advantage to improve the quality control of the whole project. Except the quality of equipments and materials, the electric project should also be closely coordinated with building projects to lay spools layer by layer and hop by hop on the basis of the schedule target of concrete deposit and the order of flow process of the civil engineering[2]. This period of work is the critical part of the entire electric installation project.

Decoration stage. Before the masonry of partition, the technician should check one time the horizontal line and partition line together with the civil engineering section chief and jug planter. Because they are the lines took by the electrician to make sure the pre-embedded position of pipeline and the location and elevation of all kinds of lamps and lanterns, switches and sockets[3]. Before plastering, the electrician should check once the obligated holes in the civil engineering based on the design and regulation of the horizontal line and partition line in the interior wall. If the holes are befit to the requirements, the electrician can stabilize the electric box.

\section{Conclusions}

Electrical engineering decoration is one part of the building electrical engineering. Being the indoor decoration practitioners or owners, they should gain some knowledge of electrical materials selection, construction points and the relation between decoration electrical and civil engineering. In this way, they could solve the application problems of electrical construction in the concrete engineering practice, so as to reduce the possibility of the issues on electrical engineering in later house usage, which plays an important role in the improvement and development of electrical construction technology.

\section{References}

[1] Zhang Yongyi. Building decoration materials [M]. Sichuan: Southwest Jiaotong University Press, 2010:167-168,169-171,172-173.

[2] Zhou Hua. Quality supervision in building electrical installation [J]. Cities and Towns Construction in Guangxi, 2007.(10):117-119.

[3] Zhao Shixin \& Xiang Jun. Construction and management technology of electromechanical installation works [J]. Shanxi Architecture, 2008.(2):193-194. 